\title{
Application of Acoustic Emission Method to Determine Critical Stress in Fibre Reinforced Mortar Beams
}

\author{
Zbigniew RANACHOWSKI, Daria JÓŹWIAK-NIEDŹWIEDZKA, \\ Andrzej M. BRANDT, Tomasz DĘBOWSKI
}

Institute of Fundamental Technological Research, Polish Academy of Sciences Pawińskiego 5B, 02-106 Warszawa, Poland; e-mail: \{zranach, djozwiak, abrandt, tdebow\}@ippt.pan.pl

(received March 12, 2012; accepted May 16, 2012)

\begin{abstract}
The objective of this investigation was to test the effectiveness of the Acoustic Emission (AE) measurements in determining the critical stresses during four-point bending of mortar beams. Within the measuring procedure the parameter $\sigma_{\mathrm{cr}} / \sigma_{300}$ was calculated and analysed. Additionally, the influence of cement replacement by high calcium fly ash (HCFA) on the process of crack healing was discussed. Mortar beams with different content of HCFA and reinforced by steel microfibres were prepared for tests. After curing in standard conditions the beams were subjected to four-point bending test in order to introduce the pre-cracking. Thereafter the beams were cured in the lime water and loaded after 56 and 112 days in the same way as for the first time. Additionally the microstructure of mortars was studied in a stereo optical microscope as well in an electron scanning microscope including the Energy Dispersive X-ray analysis (EDX). The results of microstructural characterization of mortar containing HCFA from lignite combustion are presented. The applied load level slightly exceeded the critical stress, producing intense crack growth processes however did not significant affected the load capacity of the beams. During the consecutive loading the decreasing tendency of $\sigma_{\mathrm{cr}} / \sigma_{300}$ ratio was noted. The obtained results confirm that the latter parameter can be applied as a measure of the composite degradation level for the elements carrying the repeated loads of amplitude close to the critical stress of the structure and also that the cement replacement with HCFA influences the process of crack healing.
\end{abstract}

Keywords: critical stress, Acoustic Emission, microcracking, self-healing, concrete microstructure, fly ash.

\section{Introduction}

The concrete structures are subjected to static or dynamic load and environmental interaction what collectively evoke the continuous processes of structural degradation. These processes include: loss of load bearing capacity, evolution of crack systems, deflections and deformations. The cumulation of defects imply the growth of cracks leading to the catastrophic loss of structural integrity. The effects of formation and propagation of defects significantly influence the strength and durability of concrete elements (GOLEWSKI, SADOWSKI, 2007; MARKS M. et al., 2012).

During exploitation of real structures the opposite effect to crack growth is also observed. The phenomenon of self-healing (self-regeneration, autogenous healing) in cementitious composite materials was discovered many years ago. First test results on the self-healing of cracks in concrete were published by ABrams (1917). The large study of the effect mentioned above delivered (KASPERKIEWICZ, Stroeven, 1991) who tested plain concrete beams with a central notch and recorded Crack Opening Displacement (COD). The results proved considerable influence of initial value of the preliminary crack width and only in fine microcracks appreciable healings were observed: for COD exceeding $0.3 \mathrm{~mm}$ only approx. $10 \%$ of recovery was stated. In recent papers (QJAN et al., 2010) these results have been confirmed. Mor et al. (1989) measured crack healing in lightweight concrete. Schiess, Reuter (1992) observed influence of crack healing on permeability of reinforced concrete elements. Cracks caused by freeze/thaw cycles were healed in tests by Jacobsen, Sellevold (1996), REINHARDT, Jooss (2003) determined progress of healing in relation to temperature and crack width. 
ŞAHMARAN et al. (2008) observed crack healing in concrete with high volume of standard fly ash of Class F, while WenHur et al. (2008) confirmed the influence of damage degree on healing of cracks in concrete.

Possibility of self- healing of cracks in the elements subjected to water flow was confirmed by Hosoda et al. (2009). Several investigations concerned self-healing in high performance concretes (GRANGER et al., 2009) - the results of self-healing in ultra high performance concrete with water to cement ratio $w / c=0.2$ were modelled. After curing period of 20 weeks in water, healing was observed after loaddeflection curves and acoustic emission records. Comparative tests with concretes of $w / c$ equal to 0.35 and 0.48 did not show any self-healing.

On the basis of the research cited above it may be concluded that self-healing is reported to definitely exist in cementitious composites and to influence their strength, rigidity and density, although this high potential is not explicitly employed in any design code of practice. It is believed that the self-healing of microcracks in elements subjected to bending is particularly important from practical viewpoint, because in most cases the concrete and reinforced concrete elements are used in that state of stress (GRAY, 1984; HANNAnt, Edgington, 1975; Hannant, KeER, 1983). At the preliminary stage of degradation the damages in the bulk of the concrete elements are possible to detect only with the application of sophisticated techniques, including acoustic methods (HoŁA, 1999; Ohtsu, 1996; Yuyama, Ohtsu, 2000). The most common example is using Acoustic Emission for crack formation monitoring in mechanically loaded objects (Arrington, Evans, 1977; OUYAng et al., 1991). In the research presented in (RUESCH, 1959; RANACHOWSKI et al., 2009) a remarkable progress of AE signal activity was reported related to the increase of mechanical load applied to compressed or flexured specimens made of materials with brittle matrix. Due to auxiliary tensometric measurements it could be noted that at certain stress level applied to an element a local increase of volume of damaged section is recorded due to the crack growth. The effect appears when ca. $75 \%$ of ultimate stress was exceeded. Thus the stress level mentioned above, related to remarkable AE signal activity increase was named a critical stress.

In the paper a possibility of application of $\mathrm{AE}$ method to determine the critical stresses in bending mortars with different compositions and also the experimental results of self-healing process in the beams under bending are presented. The mortars were reinforced with steel microfibers. The cement paste was partially replaced with HCFA to examine mechanical properties of such a composite material. The previous research described in (Tsimas, Moutsatsou-Tsima, 2005; JóźWIAK-NiEDŹWIEDZKA et al., 2011) let the authors to conclude that high calcium fly ash is a valu- able addition to mortars and concretes. Dispersed steel microfibers were added in order to assess the growth of cracks in a relatively brittle material. The microfibers also simulated ordinary steel reinforcement generally applied in real constructions.

It is expected that the self-healing process, if quantified in a reliable way, might be explicitly employed in design codes of practice for concrete structures. Self-healing of cracks in the reinforced concrete elements under bending may reduce permeability of external layers that provide cover for steel reinforcement against corrosive environment. Therefore, certain positive influence on durability of civil engineering structures may be expected even if only partial recovery of strength would be possible.

\section{Experimental research}

\subsection{Materials and preparation of specimens}

In all mixtures ordinary Portland Cement CEMI 42.5R (PC) and high-calcium fly ash with content of $\mathrm{CaO}$ of over $22 \%$ were used. Chemical composition of $\mathrm{PC}$ and HCFA are presented in Table 1.

Table 1. Chemical composition of Portland Cement and High Calcium Fly Ash.

\begin{tabular}{|l|c|c|}
\hline \multicolumn{1}{|c|}{ Constituent (\% by mass) } & CEM I 42.5R & HCFA \\
\hline $\mathrm{SiO}_{2}$ & 22.2 & 39.2 \\
\hline $\mathrm{Al}_{2} \mathrm{O}_{3}$ & 5.3 & 23 \\
\hline $\mathrm{Fe}_{2} \mathrm{O}_{3}$ & 3.0 & 4.95 \\
\hline$\Sigma \mathrm{SiO}_{2}+\mathrm{Al}_{2} \mathrm{O}_{3}+\mathrm{Fe}_{2} \mathrm{O}_{3}$ & 30.5 & 67.15 \\
\hline $\mathrm{CaO}$ & 66.3 & 22.4 \\
\hline $\mathrm{SO}_{3}$ & $2-6$ & 3.07 \\
\hline $\mathrm{CaO}$ free & 1.3 & 1.46 \\
\hline $\mathrm{MgO}$ & 1.3 & 1.27 \\
\hline Loss on ignition & 0.2 & 1.85 \\
\hline Glassy phase content & - & 64.23 \\
\hline
\end{tabular}

Unprocessed HCFA was applied and it contained mainly spherical particles with predominant grain size between 20 and $60 \mu \mathrm{m}$ and conglomerate both, spherical and irregular shape, size from 60 to $80 \mu \mathrm{m}$. The morphology of the HCFA particles is presented in Fig. 1.

The HCFA, a by-product of lignite burning, is captured by electrostatic precipitators. It has a form of a very fine powder, originating from the presence of highly active constituents, such as reactive lime, reactive silica and alumina. It has $\mathrm{CaO}$ content within the range from 10 to $40 \%$ and therefore so-called selfsetting is observed, and for this reason high calcium fly ash is considered as a pozzolanic and hydraulic material (Tsimas, Moutsatsou-Tsima, 2005). HCFA also contains significant amounts of calcium aluminate glass which is more soluble than the glass in low- 


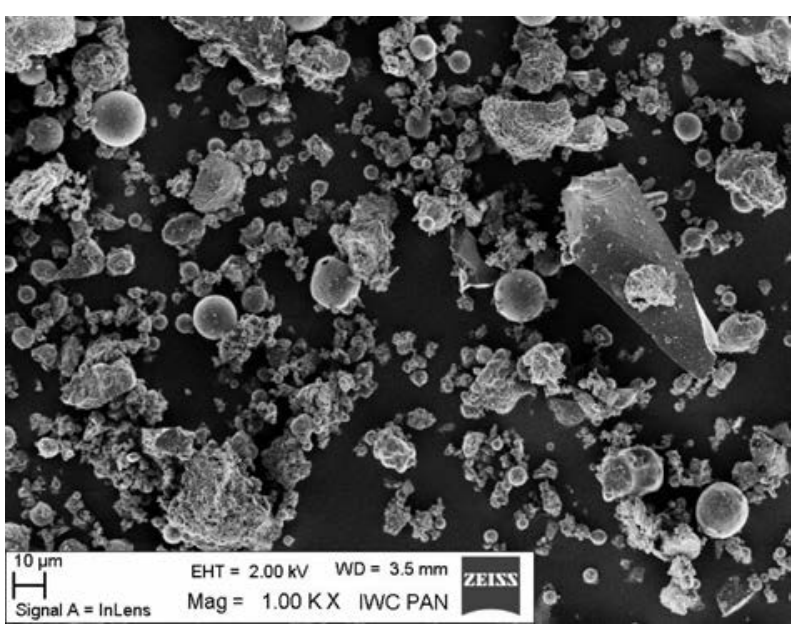

Fig. 1. SEM micrograph showing the morphology of the HCFA particles.

calcium fly ash and may slowly release calcium and aluminum into solution.

As for fine aggregate, standard siliceous sand 0-2 mm according to PN-EN 196-1 was used. The water/binder (cement + high calcium fly ash) ratio was held constant equal to 0.4. Steel microfibres Dramix OL6/.16 were used with volume fraction 1\%. These microfibres are $6 \mathrm{~mm}$ long and $0.16 \mathrm{~mm}$ in diameter, made with high-carbon steel with minimum tensile strength equal to $2000 \mathrm{~N} / \mathrm{mm}^{2}$. The mix proportions of mortar are shown in Table 2. Mortar denoted as R-0\% was the reference composition without fly ash. Other mortars R-30 and R-60 had 30 and $60 \%$ of Portland cement replaced by fly ash, respectively.

Table 2. Mortar mixture proportions in $\left[\mathrm{kg} / \mathrm{m}^{3}\right]$.

\begin{tabular}{|l|c|c|c|}
\hline \multirow{2}{*}{ Constituents } & \multicolumn{3}{c|}{ Mix ID } \\
\cline { 2 - 4 } & R-0\% & R-30\% & R-60\% \\
\hline Cement & 1000 & 700 & 400 \\
\hline Siliceous Sand (0-2.0 mm) & \multicolumn{3}{|c|}{600} \\
\hline High Calcium Fly Ash & 0 & 300 & 600 \\
\hline Water & \multicolumn{3}{|c|}{400} \\
\hline Fibers, 1\% vol. & \multicolumn{3}{|c|}{78.6} \\
\hline
\end{tabular}

The constituents were first mixed with water in a kind of Hobart mixer for 1 min thoroughly. Then fibres were added and the mixture was mixed again for $1 \mathrm{~min}$. Coupon specimens with the dimensions $240 \times 320 \times 40 \mathrm{~mm}$ were cast and cured 1 day in the moulds under sealed conditions. Then the coupons were cured in the lime water for another 27 days. When the time of pre-cracking arrived, each coupon was sawn into six beams with the dimensions of $220 \times 40 \times 40 \mathrm{~mm}$.

\subsection{Pre-cracking of specimens and program of tests}

The beams were loaded in four-point bending test where the support span was set up for $200 \mathrm{~mm}$ with the middle loading span equal to $66.7 \mathrm{~mm}$, what is presented in Fig. 2.

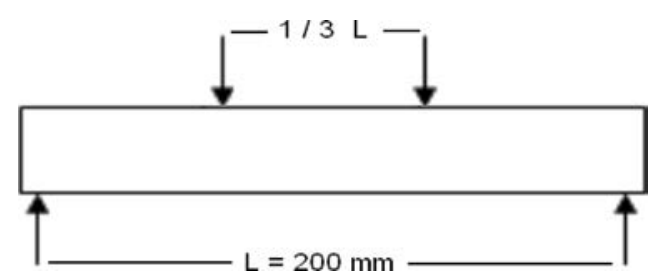

Fig. 2. Specimen under loading with two concentrated forces.

All beams were loaded up to maximum deflection equal to $0.3 \mathrm{~mm}$. This deflection was arbitrarily selected in order to obtain central crack in the beam of appropriate width for self healing. The deflection did not cause the crucial loss of beam stiffness, however its level guaranteed the excess of the critical stress in central cross-section of the sample. The tests were repeated at selected dates to register healing process in time; the test program is given in Table 3 . The acoustic emission events were recorded in order to monitor crack propagation.

Table 3. The testing program.

\begin{tabular}{|l|c|c|}
\hline & Denotation & Age since precracking [days] \\
\hline Casting & - & -28 \\
\hline Precracking & A & 0 \\
\hline Loading \#1 & B & 56 \\
\hline Loading \#2 & C & 112 \\
\hline
\end{tabular}

\subsection{Acoustic Emission measurements}

Acoustic emission effects were registered and recorded in order to monitor the progress of cracking process during loading. Registration of AE signals was performed with a wideband AE sensor of type WD PAC. A custom-made AE analyser included high-pass filter with roll-off frequency of $15 \mathrm{kHz}, 60 \mathrm{~dB}$ amplifier and fast 12 bit A/D converter to store the source signal in a PC disk. AE signals of duration longer that $100 \mu \mathrm{s}$ and which amplitudes exceeded $1 \mathrm{mV}$ were recognized due to applied software. The AE sensor was placed in the central part of the loaded beam at it lateral surface and coupled with the beam body with a silicone grease. All the 18 records of AE activity described below have revealed the excess of the critical load. At that level of stress the significant increase of AE event rate was noted. The parameter describing the flexural stress induced in beam loaded in four-point bending $\sigma_{f l}$ was calculated after the formula recommended by the ASTM C1018-94 for the case where middle span equals $1 / 3$ of the support span:

$$
\sigma_{f l}=P L /\left(b h^{2}\right) \quad[\mathrm{MPa}],
$$


where $P$ - loading force $[\mathrm{N}], L$ - support span [mm], $b$ - beam width, $h$ - beam height [mm].

Using the formula (1) the following parameters were calculated: $1-\sigma_{300}$, denoting flexural stress level at $300 \mu \mathrm{m}$ deflection and $2-\sigma_{\mathrm{cr}}$, denoting flexural stress level at critical load, whereas $\sigma_{\mathrm{cr}}<\sigma_{300}$.

\subsection{Microscopic tests methods}

The evaluation of the microstructure was performed using stereomicroscope and back scattered electron microscope (BSE). The stereomicroscope Nikon SMZ 800 and colour video camera SONY DXC 950P were used for determination of the microstructural changes in the specimens at the micro scale (magnification 63 times). In the higher magnification the specimens were examined using Scanning Electron Microscope (SEM), BSE together with Energy Dispersive $\mathrm{X}$-ray analysis (EDX). The specimens were analyzed after 1st loading (total 57 days of curing) in the SEMEDX mode on the polished surface and after 2nd loading and additional 28 days of curing in the lime water (total 170 days of curing) - in the stereomicroscope. Parallel with microscopic observations after 170 days of maturity period the SEM analysis has been executed on the split surface of the specimen.

Additionally, certain samples were analysed using Laser Scanning Confocal Microscope of LEXT type equipped with a MPALON object - lens of $20 \mathrm{X}$ magnification. Pictures made with the latter equipment were taken of surfaces polished in the same way as for the SEM analysis.

\section{Results of measurements and their analysis}

Typical experimental results obtained during precracking and after curing in lime water during 56 and 112 days respectively, are shown in Figs. 3, 4 and 5. The onset of the critical crack was marked with ' $\mathrm{x}$ ' at these Figures. The load rate was set to $25 \mathrm{~N} / \mathrm{s}$ however due to differences in stiffness within the elements of the loading machine and the concrete beam the deflection measured by the gage placed below the beam was of non-linear character. Therefore in Figs. 3-5 the load and AE events sum versus time is placed with additional marker of measured deflection at the moment when a critical stress had been reached. The analysis of the results had revealed that the consecutive loadings were of minor importance to the loss of stiffness of examined beams. It is possible that a selfhealing during a relatively long periods of curing was responsible for the effect of stiffness recovery. At this moment it seems impossible to separate the variation of stiffness due to cracking and to healing. However more distinct variations of stiffness were found out after comparison of the beams made of different mixes.

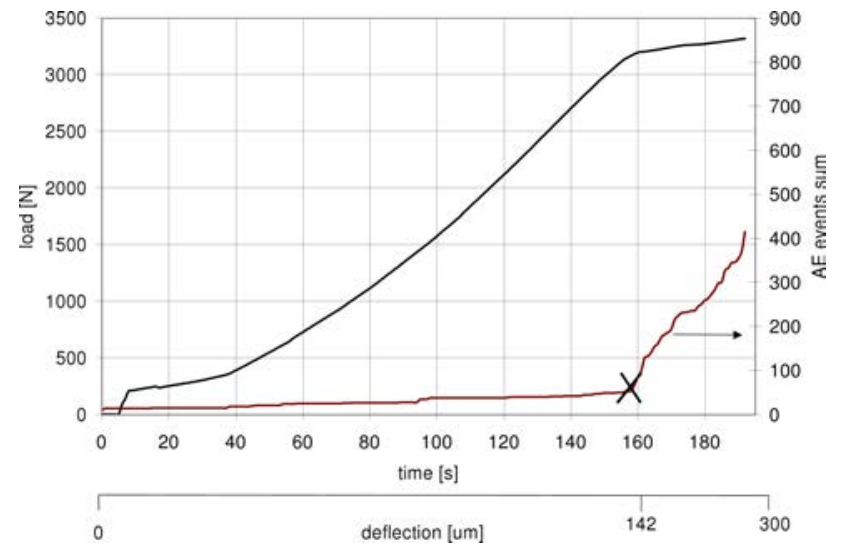

Fig. 3. Load vs. time and AE events sum vs. time recorded during pre-cracking in the beam made of a mix without HCFA admixture. A critical crack growth was detected after the deflection of $142 \mu \mathrm{m}$ was reached.

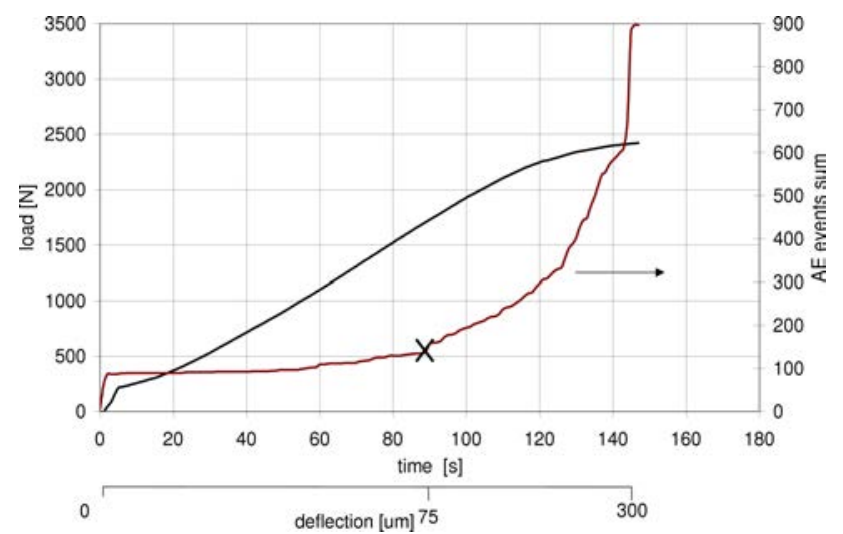

Fig. 4. Load vs. time and AE events sum vs. time recorded in the beam after 56 days of curing, made of a mix with $30 \%$ HCFA admixture. A critical crack growth was detected after the deflection of $75 \mu \mathrm{m}$ was reached.

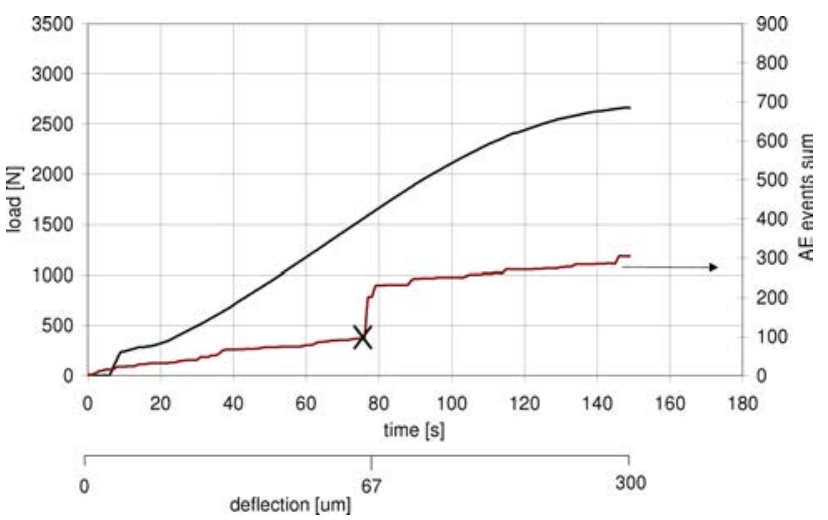

Fig. 5. Load vs. time and AE events sum vs. time recorded in the beam after 112 days of curing, made of a mix with $60 \%$ HCFA admixture. A critical crack growth was detected after the deflection of $67 \mu \mathrm{m}$ was reached.

It can be assumed that crack growth did not affected seriously the mechanical strength of the inves- 
tigated beams because the capacity of carrying the load was partly realized by the system of micro reinforcement. Therefore the beams were good models of a real reinforced elements used in civil engineering. The quantitative analysis of mechanical strength of the investigated beams was made in the following way. The results of two samples of each set (i.e. R-0\%, R-30\% and R-60\%) presenting the lowest and the highest value of $\sigma_{300}$ parameter were rejected and the other were averaged. The standard deviation calculated for the remaining 4 members did not exceeded $20 \%$ of the mean value. The mean values of flexural stress $\sigma_{300}$ calculated for three types of mixes and its changes due to consecutive loadings are presented in Table 4 and the critical value of flexural strength are presented in Table 5.

Table 4. Mean values of flexural strength $\sigma_{300}$ calculated for three types of mixes and its changes due to consecutive loadings.

\begin{tabular}{|c|c|c|c|}
\hline Mix ID & $\begin{array}{c}\sigma_{300} \\
\text { measured at } \\
\text { precracking } \\
{[\mathrm{MPa}]}\end{array}$ & $\begin{array}{c}\sigma_{300} \\
\text { measured at } \\
\text { loading \#1 } \\
{[\mathrm{MPa}]}\end{array}$ & $\begin{array}{c}\sigma_{300} \\
\text { measured at } \\
\text { loading \#2 } \\
{[\mathrm{MPa}]}\end{array}$ \\
\hline $\mathrm{R}-0 \%$ & 8.2 & 8.5 & 8.3 \\
\hline $\mathrm{R}-30 \%$ & 7.5 & 7.8 & 7.7 \\
\hline $\mathrm{R}-60 \%$ & 7.1 & 7.2 & 7.2 \\
\hline
\end{tabular}

Table 5. Mean values of flexural stress $\sigma_{\text {cr }}$ calculated for three types of mixes and its changes due to consecutive loadings.

\begin{tabular}{|c|c|c|c|}
\hline Mix ID & $\begin{array}{c}\sigma_{\mathrm{cr}} \\
\text { measured at } \\
\text { precracking } \\
{[\mathrm{MPa}]}\end{array}$ & $\begin{array}{c}\sigma_{\mathrm{cr}} \\
\text { measured at } \\
\text { loading \#1 } \\
{[\mathrm{MPa}]}\end{array}$ & $\begin{array}{c}\sigma_{\mathrm{cr}} \\
\text { measured at } \\
\text { loading \#2 } \\
{[\mathrm{MPa}]}\end{array}$ \\
\hline $\mathrm{R}-0 \%$ & 7.3 & 6.6 & 6.7 \\
\hline $\mathrm{R}-30 \%$ & 6.4 & 6.7 & 4.7 \\
\hline $\mathrm{R}-60 \%$ & 6.8 & 6.7 & 4.9 \\
\hline
\end{tabular}

The comparison of the data presented in Table 4 let the authors to conclude that a slight increase of flexural strength in examined mixes was observed after 56 days of curing (prolonged curing was not so effective). That effect may be explained by the increasing cohesion between the fibres and matrix during maturing. The other effect is that mortars with $30 \%$ (by weight) substitution of cement by HCFA admixture presented ca. $8 \%$ lower value of flexural stress than that with no admixture. $60 \%$ substitution of cement by HCFA resulted in ca. $15 \%$ decrease of the flexural stress. The critical value of flexural strength is influenced significantly and decreasing by the number of loadings. That means that $\sigma_{\text {cr }}$ reflects the structure degradation due to crack growth. To demonstrate the latter tendency in the Table $6 . \sigma_{\mathrm{cr}}$ was laid as a ratio of the correspond-
Table 6 . The measure of structural degradation expressed as a ratio of $\sigma_{\mathrm{cr}} / \sigma_{300}$ calculated for data presented in Tables 4 and 5 .

\begin{tabular}{|c|c|c|c|}
\hline Mix ID & $\begin{array}{c}\sigma_{\mathrm{cr}} / \sigma_{300} \\
\text { precracked } \\
\text { beams }\end{array}$ & $\begin{array}{c}\sigma_{\mathrm{cr}} / \sigma_{300} \\
\text { loading \#1 }\end{array}$ & $\begin{array}{c}\sigma_{\mathrm{cr}} / \sigma_{300} \\
\text { loading \#2 }\end{array}$ \\
\hline R-0\% & 0.90 & 0.77 & 0.81 \\
\hline R-30\% & 0.86 & 0.86 & 0.60 \\
\hline R-60\% & 0.93 & 0.93 & 0.67 \\
\hline
\end{tabular}

ing value of $\sigma_{300}$. That ratio is proposed to be used as a clear measure of stage of structural degradation.

\section{Microscopic observations}

Figure 6 presents an example of the general view of the observed cracking surface, taken with the use of optical microscopy. The separate mortar constituents are visible: fine aggregate - sand, spherical particles of high calcium fly ash, and steel fibres (the latter visible as white needles). Steel fibres tend to stop crack propagation. The image of the observed main crack taken in the confocal laser scanning microscope (Fig. 7) demonstrates the depth of the crack propagation which arrives to about $400 \mu \mathrm{m}$.

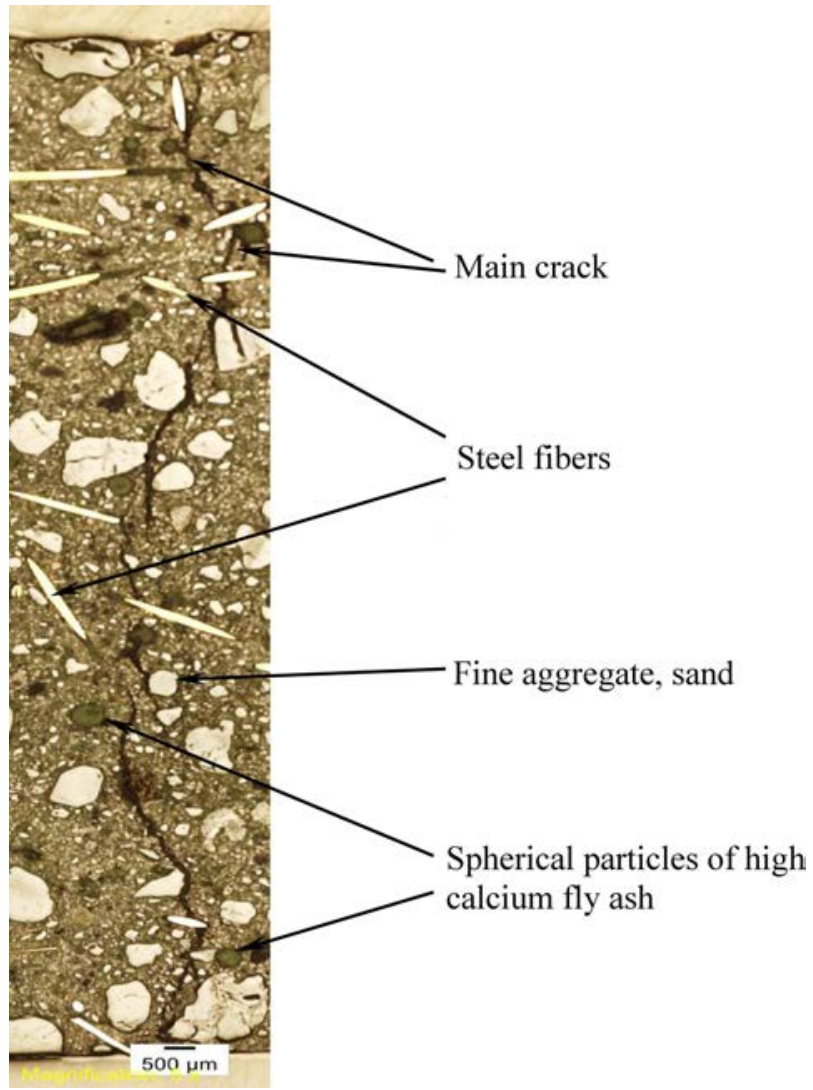

Fig. 6. Microphotograph of the observed cracking surface, mix of R-60\% type, thin white 'needles' are images of microfiber fragments. 


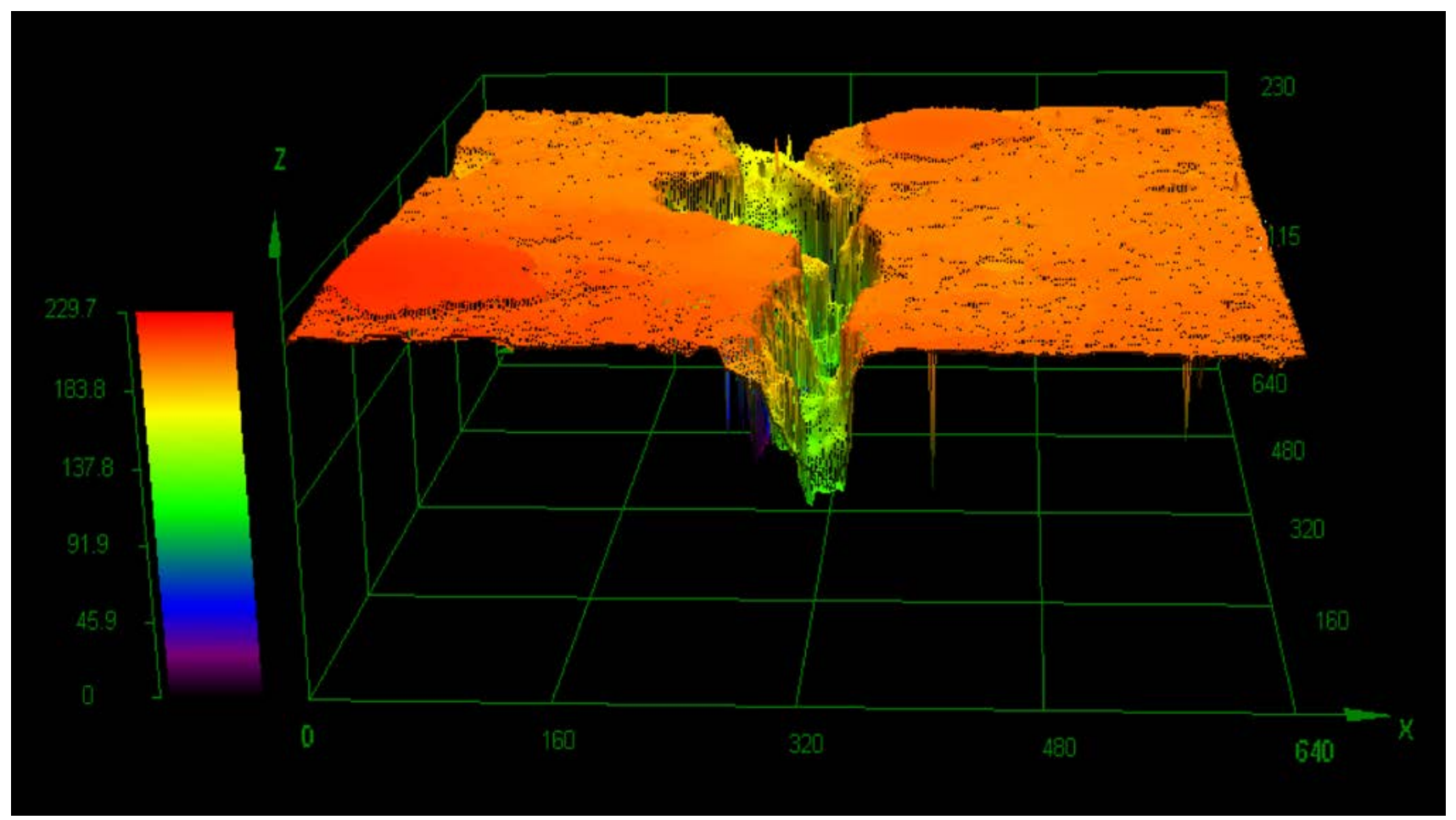

Fig. 7. Image created of data recorded with confocal laser scanning microscope, demonstrating the real depth of cracked concrete matrix, arriving to $400 \mu \mathrm{m}$. The color mapping was used to present the local depression of the surface.

Figure 8 presents an example of the crack system consisting of the main crack which propagates through the whole specimen (width about $100 \mu \mathrm{m}$ ) and the fine microcrack (width about less than $30 \mu \mathrm{m}$ ) which is parallel to the main crack.

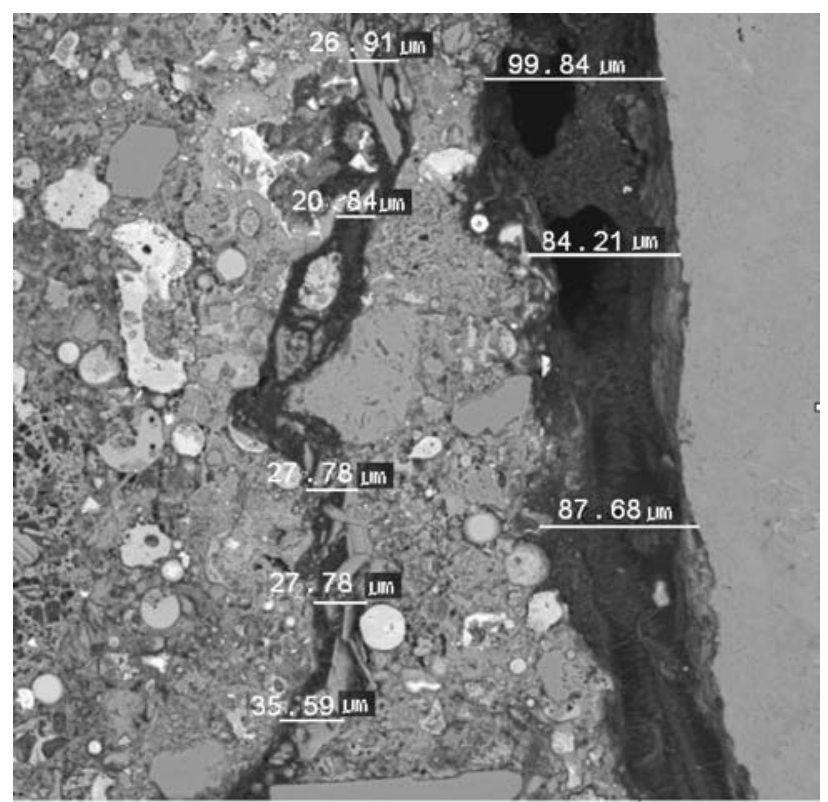

Fig. 8. Microphotograph of the crack system consisting of the single microcrack, (central part of the cross-section) and the main crack, situated to the right from the microcrack.

\section{Conclusions}

In the paper the mechanical testing of mortar elements with high calcium fly ashes was presented. HCFA were used as a partial cement replacement in mortar beams to increase the self-healing phenomenon in cracks and to tighten the structure of concrete. The beams were subjected to 4-point bending until opening of a system of microcracks and cracks. After specific period of time the beams structure was analyzed using stereomicroscope and SEM.

With regard to the main findings of the present work, these are summarized as follows:

- Limited increase of stiffness of specimens after 56 and 112 days of curing due to crack healing is shown on load- deflection curves. Considering the data presented in Table 6 the relative recovery of stiffness due to crack healing, (i.e. initial to final stiffness level) can be estimated to $60-80 \%$. The highest effect of healing was measured in mix with no HCFA admixture.

- Due to good bond between the micro reinforcement and the matrix the process of crack growth was successfully blocked,

- The analysis of the recorded Acoustic Emission activity has revealed that the HCFA admixture decreased the overall beam stiffness measured under bending and also that the critical stress level, possible to determine with the application 
of acoustic method is close to the stage of degradation processes induced by multiple loading of reinforced concrete object.

More information on load-deflection behaviour of tested beams is presented in JóźWIAK-NIEDŹWIEDZKA et al. (2012).

\section{Acknowledgment}

The experimental work concerning SEM-BSE analysis presented in this study was conducted in the Charles Pankow Concrete Materials Laboratory at Purdue University. The authors gratefully acknowledge the support at that part of the presented investigation.

The authors are thankful to Bekaert Poland Sp. z o.o. for complimentary supply of microfibers.

The results presented in the paper have been obtained within the project "Innovative cement binders and concretes with addition of high calcium fly ash" (project no POIG.01.01.02-24-005/09 with the Polish Ministry of Science and Higher Education) in the framework of the Operational Programme Innovative Economy 2007-2013.

\section{References}

1. Abrams D.A. (1917), Effects of rate of application of load on the compressive strength of concrete, Amer. Soc. For Testing of Materials, Proc. 17, part II, 364377 .

2. Arrington M., Evans B.M. (1977), Acoustic emission testing of high alumina cement concrete, NDT Int., 10, 2, 81-87.

3. Golewski G., Sadowski T. (2007), Analysis of brittle damages in concrete composites [in Polish], Proc. of Cracow University of Technology, Civil Engineering, 1-B, 4, 55-62.

4. Granger S., Pijaudier G., Loukili A., MarLOT D., LenAin J.C. (2009), Monitoring of cracking and healing in an ultra high performance cementitious material using the time reversal technique, Cem. \& Concr. Res., 39, 296-302.

5. Gray R.J. (1984), Autogeneous healing of fibre/matrix interfacial bond in fibre-reinforced mortar, Cem. \& Concr. Res., 14, 315-317.

6. Hannant D.J., Edgington J. (1975), Durability of steel fibre concrete, [in:] Proc. RILEM Symp. "Fibre reinforced cement and concrete", Lancaster; Construction Press, 159-169.

7. Hannant D.J., Keer J.G. (1983), Autogeneous healing of thin cement based sheets, Cem. \& Concr. Res., 13, 533-538.

8. HoŁa J. (1999), Acoustic Emission investigation of failure of high-strength concrete, Archives of Acoustics, 24, 2, 233-244.
9. Hosoda A., Komatsu S., Ahn T., Kishi T., IkeNo S., Kobayashi K. (2009), Self healing properties with various crack widths under continuous water leakage, in: Concr. Repair, Rehab. and Retrofit., II, Alexander et al. [Eds.], Taylor and Francis, 221-227.

10. Jacobsen S., Sellevold E.J. (1996), Self healing of high strength concrete after deterioration by freeze/thaw, Cem. \& Concr. Res., 26, 1, 55-62.

11. JóŹWiak-NiedźWiedzka D., Gibas K., GliniCKI M.A., Nowowiejski G. (2011), Tightness of the concretes with high calcium fly ash admixture in relation to diffusion of aggressive agents [in Polish: Drogi $i$ Mosty], Journal of Polish Institute of Roads and Bridges, 3, 39-61.

12. Jóźwiak-Niedźwiedzka D., Brandt A.M., RanaCHOWsKi Z. (2012), Self-healing of cracks in fibre reinforced mortar beams made with high calcium fly ash, Cement, Wapno, Beton (www.cementwapnobeton.pl), 1, 38-49.

13. Kasperkiewicz J., Stroeven P. (1991), Observations on crack healing in concrete, [in:] Proc. Int. Symp. "Brittle Matrix Composites 3" Warszawa, Appl. Sc. Publ., 164-173.

14. Marks M., Jóźwiak-Niedźwiedzka D., GlinicKI M.A. (2012), Automatic categorization of chloride migration into concrete modified with CFBC ash, Computers and Concrete, 9, 5, 375-387.

15. Mor A., Monteiro P.J.M., Hester W.T. (1989), Observations of healing of cracks in high-strength lightweight concrete, Cem. Concr. and Aggr., 11, 2, $121-125$.

16. Ohtsu M. (1996), The history and development of acoustic emission in concrete engineering, Magazine of Concrete Res., 48, 321-330.

17. Ouyang C.S., Landis E., Shah S.P. (1991), Damage assesment in concrete using quantitative acoustic emission, J. Eng. Mech., 117, 11, 2681-2698.

18. Qjan S.Z., Zhou J., Schlangen E. (2010), Influence of curing condition and precracking time on the selfhealing behavior of Engineered Cementitious Composites, Cem. \& Concr. Comp., 32, 686-693.

19. Ranachowski P., Rejmund F., Ranachowski Z., PaweŁek A., PiątKowski A. (2009), Comparison of Acoustic Emission and Structure Degradation in Compressed Porcelain and Corrundum Materials, Archives of Acoustics, 34, 4, 566-676.

20. Reinhardt H.W., Jooss M. (2003), Permeability and self-healing of cracked concrete as a function of temperature and crack width, Cem. \& Concr. Res., 33, 981985 .

21. Ruesch H. (1959), Physical problems in the testing of concrete, Zement, Kalk, Gips, 12, 1, 1-9.

22. Şahmaran M., Keskin S.B., Ozerkan G., YaMAN I.O. (2008), Self-healing of mechanically-loaded 
self consolidating concretes with high volumes of fly ash, Cem. \& Concr. Comp., 30, 872-879.

23. Schiessl P., Reuter C. (1992), Massgebende Einflussgrössen auf die Wasserdurchlässigkeit von gerissenen Stahlbetonbauteilen, Ann. Report, Institüt für Bauforschung, Aachen, 223-228.

24. Tsimas S., Moutsatsou-Tsima A. (2005), Highcalcium fly ash as the fourth constituent in concrete: problems, solutions, and perspectives, Cem. Concr. Comp., 27, 231-237.

25. Wenhui Zhong, Wu Yao (2008), Influence of damage degree on self-healing of concrete, Constr. \& Build. Materials, 22, 1137-1142.

26. Yuyama S., Ohtsu M. (2000), Acoustic Emission evaluation in concrete [in:] Kishi T., Ohtsu M., Yuyama S. [Eds.], Acoustic Emission-Beyond the Millennium, Elsevier, 187-213. 